\title{
Bacteriophage PBSX-induced Deletion Mutants of Bacillus subtilis 168 Constitutive for Alkaline Phosphatase
}

\author{
By P. J. PIGGOT AND R. S. BUXTON* \\ Division of Microbiology, National Institute for Medical Research, Mill Hill, \\ London NW7 1AA, U.K.
}

(Received 24 July 1981)

\begin{abstract}
Mutants of Bacillus subtilis with deletions extending from the PBSX prophage, and in some cases removing $\operatorname{pro}(A B)$ and metC, have been found to be constitutive for vegetatively synthesized alkaline phosphatase. Such deletions were isolated by selecting for heat-resistant derivatives of a strain carrying a xhi-1479 mutation causing heat-inducibility of the defective phage PBSX. These deletions remove the phoS gene, a regulatory gene for alkaline phosphatase; it is concluded that the phoS gene product exerts negative control on alkaline phosphatase synthesis. Deletion mapping, combined with previously published linkage data, indicates a gene order of PBSX-phoS-pro $(A B)$-metC.
\end{abstract}

\section{INTRODUCTION}

Alkaline phosphatase synthesis by Bacillus subtilis is repressed by inorganic phosphate during exponential growth (Anagnostopoulos, 1960). Mutations in three loci, phoR (Le Hégarat \& Anagnostopoulos, 1969; Miki et al., 1965; Nukushina \& Ikeda, 1969), phoS (Piggot \& Taylor, 1977) and phoT (Piggot et al., 1981), result in constitutive enzyme formation, whereas mutation in a fourth gene, phoP, causes alkaline phosphatase to be completely repressed (Le Hégarat \& Anagnostopoulos, 1969; Miki et al., 1965; Nukushina \& Ikeda, 1969). Other controls apparently operate during sporulation where the enzyme is formed in the presence of inorganic phosphate. Mutation in any one of 14 spo loci prevents this synthesis whilst mutation in $\operatorname{sapA}$ or $\operatorname{sap} B$ overcomes the effects of the spo mutations (Piggot \& Coote, 1976; Piggot \& Taylor, 1977; P. J. Piggot, unpublished observations). Nothing is yet known, however, of how any of these loci exert their control on the synthesis of alkaline phosphatase.

One very good criterion for determining whether a gene is regulated by positive or negative control is the characterization of deletions of the regulatory gene (see, for example, Beckwith \& Rossow, 1974). Constitutive expression should result from deletion of a regulatory gene exerting negative control, whereas loss of expression should result from the deletion of a regulatory gene operating by positive control. Such a method has been used to demonstrate positive control of alkaline phosphatase synthesis by the $p h o B$ gene product in Escherichia coli (Brickman \& Beckwith, 1975). Until recently, however, this type of analysis has not been possible in $B$. subtilis, because no method has been available to delete parts of the chromosome. This has been remedied by the isolation of prophage mutations causing heat-inducibility of the defective bacteriophage PBSX (xhi-1479) (Buxton, 1976), and of bacteriophage SP $\beta$ (c2) (Rosenthal et al., 1979). Thus, it is possible to generate deletions in the region adjacent to the PBSX prophage by selecting for heat-resistant derivatives of the xhi mutant (Buxton, 1980). Coincidentally, two of the loci regulating alkaline phosphatase synthesis, phoS and sapA, map in the region of the chromosome adjacent to the PBSX prophage (Buxton, 1980; Piggot \& Taylor, 1977). We have therefore generated deletions in this region and we show that these mutants produce alkaline phosphatase constitutively in vegetative growth. 
Table 1. Strains of Bacillus subtilis used

Strain

RB 1037

RB 1081

RB 1084

RB 1180

RB1183

RB 1184

RB1190

RB1193

RB 1388

SL321

SL340

SL344

SL345

SL349

SL351

SL652

SL1053

SL1059
Genotype

pyrX* $x h i-1479 \dagger x k i-1479 \ddagger$

pyrX $\Delta(\mathrm{PBSX}-$ phoS-pro $(A B))$

pyrX $\triangle(\mathrm{PBSX}-$ phoS-pro $(A B)-$ metC $)$

pyrX $x h i-1479 \times k i-1479$ rif-2 spolla69

pyrX $\Delta(\mathrm{PBSX})$, or $x h i^{+}$

pyrX $\Delta$ (PBSX), or $x$ hi $^{+}$, rif-2 spoIIA69

pyrX $\Delta$ (PBSX-phoS) rif-2 spolla69

pyrX $\triangle(\mathrm{PBSX}$-phoS-pro $(A B)-$ metC) rif-2

spoIIA69

trpC2

sapB2 leuA8 rif-2 spolIG55

phoS5 rif-2 spoIIA69

phoS5 leuA8 tal-1§

phoS5 leuA8 rif-2 spoIIE64

sapA6 leuA8 tal-1

sapA6 leuA8 tal-1 rif-2 spoIIE64

purB6 rif-2 spoIIA69

pyrX $\Delta(\mathrm{PBSX}-$ phoS-pro $(A B)-$ metC $)$ rif-2 spoIIA69

pyrX $\Delta(\mathrm{PBSX}-$ phoS $)$ rif-2 spo ${ }^{+}$
Origin or reference

Buxton (1980)

Heat ${ }^{\mathrm{r}}$ derivative of RB1037. Buxton (1980)

Heat $^{\mathrm{r}}$ derivative of RB1037. Buxton (1980)

DNA.SL652 $\times$ RB1037 $\rightarrow$ Rif $^{r}$

Heat $^{\mathrm{r}}$ derivative of RB1037

Heat ${ }^{\mathrm{t}}$ derivative of RB 1180

Heat $^{\mathrm{r}}$ derivative of RB 1180

Heat $^{\mathrm{r}}$ derivative of RB1180

M. M. McConnell

Previously designated 300.16. Piggot \& Taylor (1977)

Previously designated 305.1. Piggot \& Taylor

Previously designated 305.7. Piggot \& Taylor

DNA.64.1 (Piggot \& Taylor, 1977) $\times$ SL344 $\rightarrow$ Rif ${ }^{r}$

Previously designated 306.7. Piggot \& Taylor (1977)

DNA.64.1 $\times$ SL349 $\rightarrow$ Rif $^{t}$

Previously designated 69.3. Piggot \& Taylor (1977)

DNA.SL652 $\times$ RB1084 $\rightarrow$ Rif $^{r}$

DNA.168 $\times$ RB1190 $\rightarrow$ Spo $^{+}$

* Although previously described as pyrA (Buxton, 1976, 1980), from the origin and phenotype of the strain we now believe this to be $p y r X$ (see Potvin et al., 1975).

$\dagger x h i-1479$ is a prophage mutation of the defective phage PBSX causing heat-induction of this phage.

$\ddagger x k i-1479$ is a prophage mutation of PBSX causing the PBSX produced to have no killing activity on the sensitive strain W23.

$\S$ tal-1 is a mutation causing resistance to $\beta$-thienylalanine.

\section{METHODS}

Bacterial strains. The bacterial strains used are listed in Table 1.

Media. Minimal agar was T-S agar based on Spizizen's salts (see Buxton, 1976). L-agar contained, per litre: Difco tryptone, $10 \mathrm{~g}$; Difco yeast extract, $5 \mathrm{~g} ; \mathrm{NaCl}, 10 \mathrm{~g}$; Difco agar, $16 \mathrm{~g}$; adjusted to $\mathrm{pH}$ 7. Modified Schaeffer's medium (MSM) contained, per litre: Difco nutrient broth, $16 \mathrm{~g} ; \mathrm{MgSO}_{4} .7 \mathrm{H}_{2} \mathrm{O}, 0.5 \mathrm{~g} ; \mathrm{KCl}, 2 \mathrm{~g}$; adjusted to $\mathrm{pH}$ 7. This was freshly prepared, or re-steamed prior to use. $\mathrm{Ca}\left(\mathrm{NO}_{3}\right)_{2}$ (final concn $10^{-3} \mathrm{M}$ ), $\mathrm{MnCl}_{2}$ $\left(10^{-4} \mathrm{M}\right), \mathrm{FeSO}_{4}\left(10^{-6} \mathrm{M}\right)$ and glucose $(0.1 \%, \mathrm{w} / \mathrm{v})$ were added before use (Leighton \& Doi, 1971). For MSM agar, $1.5 \%$ Difco agar was added.

Estimation of growth rates. Samples $(0.6 \mathrm{ml})$ were added to $0.6 \mathrm{ml} 10 \%$ formalin and the absorbance was measured at $600 \mathrm{~nm}$ using a Pye Unicam SP6-550 spectrophotometer. The $A_{600}$ was converted to bacterial dry wt $\mathrm{ml}^{-1}$ by means of a standard calibration curve.

Selection of heat-resistant derivatives of a Xhi- strain. Heat-resistant derivatives were selected for growth at $48^{\circ} \mathrm{C}$ on Schaeffer's agar as described previously (Buxton, 1980).

Plate test for alkaline phosphatase. This was carried out as described previously (Piggot \& Taylor, 1977) except that bacteria were grown on MSM agar.

Assay for alkaline phosphatase. This was performed using p-nitrophenyl phosphate as substrate in $0.5 \mathrm{M}$ diethanolamine $/ \mathrm{HCl}, \mathrm{pH} 10$, at $30^{\circ} \mathrm{C}$, as described by Glenn \& Mandelstam (1971). The spectrophotometer was calibrated with a standard solution of $p$-nitrophenol (Sigma). One unit of alkaline phosphatase activity is defined as the amount that catalyses the hydrolysis of $1 \mathrm{nmol} p$-nitrophenyl phosphate in $1 \mathrm{~min}$. Specific activities are expressed as units (mg bacterial dry wt) ${ }^{-1}$.

Transformation. Transforming DNA was extracted as described by Marmur (1961). Competent bacteria were prepared according to Bott \& Wilson (1968). 
RES ULTS

Isolation of deletion mutants that synthesize alkaline phosphatase constitutively

The $x h i-1479$ mutation results in the heat-inducibility of prophage PBSX. Thus, a $x h i-$ 1479 strain grows at $35^{\circ} \mathrm{C}$ but lyses at $48^{\circ} \mathrm{C}$ because of PBSX production (Buxton, 1976). Heat-resistant derivatives have been isolated which have deletions of all or part of the PBSX prophage together with some of the adjacent chromosome where the $\operatorname{pro}(A B)$ and $\operatorname{met} C$ loci are situated (Buxton, 1980). These deletion mutants, identified on the basis of their auxotrophy ( $\mathrm{Pro}^{-}$or $\mathrm{Pro}^{-} \mathrm{Met}^{-}$), were tested for formation of alkaline phosphatase during vegetative growth in the presence of inorganic phosphate, and all (three $\mathrm{Pro}^{-}$, and seven Pro $^{-} \mathrm{Met}^{-}$) were found to be constitutive. This suggested that deletion of a locus mapping near metC (Piggot \& Taylor, 1977) resulted in constitutive alkaline phosphatase synthesis. The locus was tentatively identified as phoS since this locus had been mapped near to metC, and phoS mutations caused constitutive enzyme synthesis (Piggot \& Taylor, 1977).

In order to look for more such deletions, we constructed a $x h i-1479$ strain (RB1180) in which the spoIIA69 mutation was introduced by transformation. The spoIIA mutation prevented the phosphate-insensitive formation of alkaline phosphatase that occurs during spore formation, thus making it much easier to distinguish between strains constitutive and non-constitutive for enzyme formation during vegetative growth.

Ten separate cultures of RB1180 were grown at $32^{\circ} \mathrm{C}$ in L-broth, and from each a single plate of MSM was inoculated with approximately $4 \times 10^{7}$ bacteria. These plates were incubated at $48^{\circ} \mathrm{C}$ and gave an average of 85 colonies per plate. The colonies were replicated on to MSM, incubated at $48^{\circ} \mathrm{C}$, and also on to minimal agar, incubated at $35^{\circ} \mathrm{C}$. The master plates were then stained for alkaline phosphatase. In this way, putative phosphataseconstitutive colonies were identified. These were picked from the replica-plates and purified by single colony isolation on L-agar. By comparing the two types of replica-plates, auxotrophic mutants were also isolated.

Sixteen mutants constitutive for alkaline phosphatase were isolated in this way (approximately $2 \%$ of the heat-resistant colonies). They were derived from separate initial colonies and were therefore of independent origin. Three of the 16 mutants required proline and methionine for growth in addition to the uracil needed by the parental strain. These presumably had deletions from the PBSX prophage removing $\operatorname{pro}(A B)$ and $\operatorname{metC}$ (Buxton, 1980) [the methionine requirement was not satisfied by cystathionine or homocysteine; this is characteristic of a lesion in metC but not metA which also maps in the vicinity (see Garro et al., 1970)]. No auxotrophic mutants were found that were not constitutive for alkaline phosphatase.

Taken together with the previously isolated deletion mutants (Buxton, 1980) selected on the basis of auxotrophy, four classes (numbered I to IV, Table 2) of heat-resistant derivatives could be distinguished. Type I could include, besides short deletions, some $x h i^{+}$revertants. For this reason, it is not possible to quantify the frequency of deletion formation, or the proportion of all deletions that had become alkaline phosphatase-constitutive.

The published three-point linkage data (Buxton, 1976, 1980) gives an order of markers in

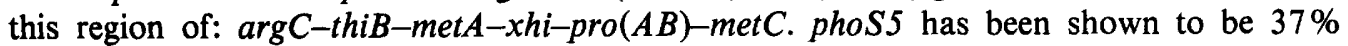
cotransducible with $\arg C$ and $77 \%$ cotransducible with metC (Piggot \& Taylor, 1977), and this is compatible with a position for phoS between $x h i$ and $\operatorname{pro}(A B)$ (see Fig. 1). The phenotypes of the deletion mutants support this conclusion, with mutants of classes I to IV representing progressively longer deletions extending from $x h i$ through $\operatorname{phoS}, \operatorname{pro}(A B)$ and metC.

\section{Mapping of an alkaline phosphatase-constitutive deletion mutant with respect to phoS and sapA}

To confirm that phoS was indeed deleted, genetic crosses were performed between strains having a point mutation in phoS and a strain with a short deletion (RB1190) (Table 3). The 
Table 2. Phenotypic classification of deletion mutants

Heat-resistant derivatives of RB1037 ( $x$ hi pyrX) and RB1180 (xhi pyrX rif spollA) were selected at $48{ }^{\circ} \mathrm{C}$. Deletion mutants were identified $(a)$ from RB1037 as having an additional auxotrophic requirement besides $\mathrm{Ura}^{-}$, and $(b)$ from RB 1180 as producing alkaline phosphatase in the presence of phosphate.

\begin{tabular}{|c|c|c|c|c|c|c|}
\hline \multirow[b]{2}{*}{ Class } & \multirow{2}{*}{$\begin{array}{l}\text { Growth } \\
\text { on L-agar } \\
\text { at } 48^{\circ} \mathrm{C}\end{array}$} & \multicolumn{3}{|c|}{ Auxotrophic phenotype } & \multirow{2}{*}{$\begin{array}{c}\text { Alkaline } \\
\text { phosphatase } \\
\text { constitutivity }\end{array}$} & \multirow[b]{2}{*}{ Strain* } \\
\hline & & Ura & Pro & Met & & \\
\hline Parent & - & - & + & + & - & RB1037 (a) \\
\hline Parent & - & - & + & + & - & RB1180 (b) \\
\hline I & + & - & + & + & - & $\operatorname{RB} 1183(a)$ \\
\hline I & + & - & + & + & - & RB $1184(b)$ \\
\hline II & + & - & + & + & + & RB1 $190(b)$ \\
\hline III & + & - & - & + & + & RB $1081(a)$ \\
\hline IV & + & - & - & - & + & RB $1084(a)$ \\
\hline IV & + & - & - & - & + & RB1193 (b) \\
\hline
\end{tabular}

* Representative strains only are given for heat-resistant mutants. The parental strain is indicated in parentheses - RB1037 as (a), RB1180 as (b).

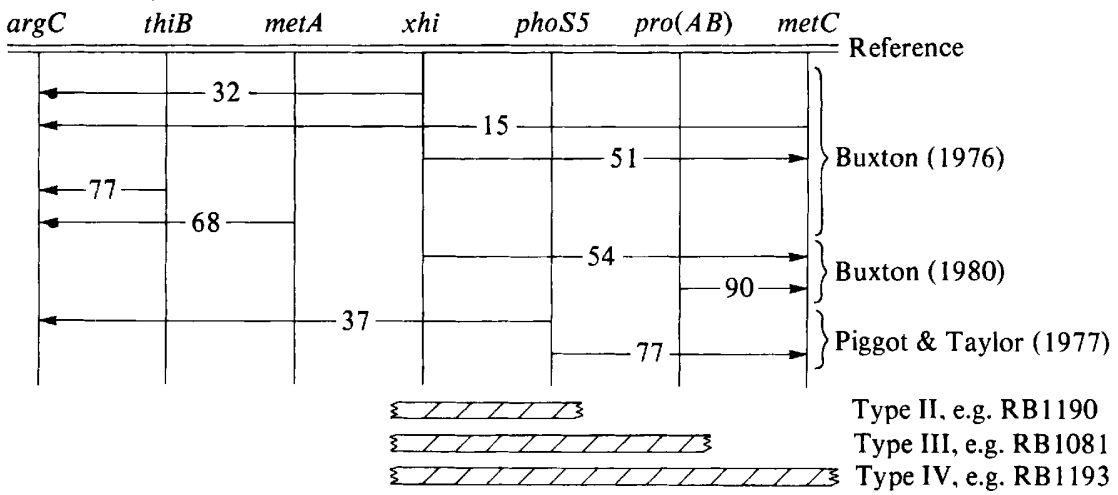

Fig. 1. Linkage map derived from published linkage data, showing the extent of the deletions mentioned in the text. The numbers refer to percentage cotransduction using PBS1; arrowheads point in the direction of selected markers.

Table 3. Transformation crosses between $\Delta p h o$, and phoS and sap strains

\begin{tabular}{|c|c|c|c|c|}
\hline \multirow[b]{2}{*}{ Donor } & \multirow[b]{2}{*}{$\begin{array}{c}\text { Colony } \\
\text { phenotype }\end{array}$} & \multicolumn{3}{|c|}{ No. of transformant colonies* } \\
\hline & & $\begin{array}{c}\text { SL351 } \\
\text { (sapA6 leuA8 } \\
\text { spoIIE64) }\end{array}$ & $\begin{array}{c}\text { Recipient: } \\
\text { SL345 } \\
\text { (phoS5 leuA8 } \\
\text { spoIIE64) }\end{array}$ & $\begin{array}{c}\text { SL321 } \\
\text { (sapB2 leuA8 } \\
\text { spoIIG55) }\end{array}$ \\
\hline SL340 (phoS5) & $\begin{array}{l}\mathrm{Leu}^{+} \\
\mathrm{Pho}^{-}\end{array}$ & $\begin{array}{r}16000 \\
7\end{array}$ & $\begin{array}{r}3420 \\
0\end{array}$ & $\begin{array}{r}1620 \\
15\end{array}$ \\
\hline RB1190 (Apho) & $\begin{array}{l}\mathrm{Leu}^{+} \\
\mathrm{Pho}^{-}\end{array}$ & $\begin{array}{r}25700 \\
0\end{array}$ & $\begin{array}{r}4680 \\
1\end{array}$ & $\begin{array}{r}1110 \\
21\end{array}$ \\
\hline $168\left(\mathrm{pho}^{+} \mathrm{sap}^{+}\right)$ & $\begin{array}{l}\mathrm{Leu}^{+} \\
\mathrm{Pho}^{-}\end{array}$ & $\begin{array}{c}2000^{\dagger} \\
76\end{array}$ & $\begin{array}{r}2900 \\
28\end{array}$ & $\begin{array}{r}500 \\
7\end{array}$ \\
\hline
\end{tabular}

* For $\mathrm{Leu}^{+}$transformants, the numbers counted have been corrected for dilution so as to give the estimated number of colonies on the plates from which the values for $\mathrm{Pho}^{-}$colonies were obtained.

$\dagger$ Number not corrected for dilution; estimated on a crowded plate. 
Table 4. Alkaline phosphatase activity in bacteria growing exponentially in Modified Schaeffer's medium at $37^{\circ} \mathrm{C}$

\begin{tabular}{|c|c|c|}
\hline Strain & Relevant genotype & $\begin{array}{l}\text { Alkaline phosphatase } \\
\text { specific activity } \\
{[\text { units (mg dry wt })^{-1} \text { ] }}\end{array}$ \\
\hline \multicolumn{3}{|c|}{ Heat-resistant derivatives of $x h i-1479$ strains } \\
\hline $\begin{array}{l}\text { RB1190 } \\
\text { SL1053 } \\
\text { RB } 1084 \\
\text { RB1183 }\end{array}$ & $\begin{array}{l}\Delta(\text { phoS }) \text { rif-2 spoIIA69 } \\
\Delta(\text { phoS-pro-metC }) \text { rif-2 spoIIA69 } \\
\Delta(\text { phoS-pro-metC }) \\
\text { pho }{ }^{+}\end{array}$ & $\begin{array}{r}19 \cdot 6 \\
18.4 \\
8 \cdot 8 \\
0.6\end{array}$ \\
\hline \multicolumn{3}{|c|}{ Strains with point mutations in $p h o S$ and $\operatorname{sap} A$} \\
\hline $\begin{array}{l}\text { SL340 } \\
\text { SL344 } \\
\text { SL349 }\end{array}$ & $\begin{array}{l}\text { phoS5 rif-2 spoIIA69 } \\
\text { phoS5 } \\
\text { sapA6 }\end{array}$ & $\begin{array}{r}22 \cdot 6 \\
8 \cdot 4 \\
0.9\end{array}$ \\
\hline
\end{tabular}

sapA locus also used in these crosses is close to, or identical to, phoS (Piggot \& Taylor, 1977); sapA mutations affect the formation of alkaline phosphatase during sporulation, but not vegetative growth.

There is no direct selection for $p h o S^{+}$(or $s a p^{+}$) and no suitable selective marker that is linked by transformation to phoS. This necessitated selection for an unlinked marker $\left(l e u^{+}\right)$ using a saturating concentration of DNA; under such conditions up to about $5 \%$ of the prototrophic transformants would be expected to receive an unlinked marker, such as pho, as a result of a second transformation event (congression). Only this small proportion of the transformants can be regarded as 'useful' with respect to analysis of pho. The pho recombinants were detected as phenotypically $\mathrm{Pho}^{-}$colonies amongst large numbers of $\mathrm{Pho}^{+}$ colonies. Donor DNA preparations were used at $10 \mu \mathrm{g} \mathrm{ml}^{-1}$ which is saturating for these purposes, and all gave rise to reasonable congression frequencies when tested with a recipient, SL321, harbouring the unlinked sapB2 mutation (Table 3). The recipient strains SL351 and SL345 gave $3.8 \%$ and $1 \%$ congression, respectively, of $\mathrm{Pho}^{-}$with selection for $\mathrm{leu}^{+}$when the parental strain 168 was used as donor. With RB1190 as donor, no Pho recombinants were obtained with SL351 $\left(<0.004 \%\right.$ of $\left.l e u^{+}\right)$and only one colony with SL345 $\left(<0.025 \%\right.$ of $\left.l e u^{+}\right)$. With SL340 (phoS5) as donor and SL351, carrying the closely linked sapA6 mutation, as recipient, seven $\mathrm{Pho}^{-}$colonies $\left(0.05 \%\right.$ of $\left.l e u^{+}\right)$were obtained.

The direct phosphatase staining procedure used killed the bacteria so that it was not possible to confirm the initial scoring by subculturing presumed $\mathrm{Pho}^{-}$colonies (the alternative of replica-plating gave too many false negatives to be practicable). It is concluded that the deletion in RB1190 probably covers phoS5 and sapA6, although it is possible that it ends short of, but very close to, these mutations.

\section{Kinetics of alkaline phosphatase formation by the deletion mutants}

All mutants deleted in the region of PBSX grew poorly in minimal media, and so enzyme formation was studied in bacteria growing exponentially in MSM. Under these conditions, pho ${ }^{+}$strains (RB1183, Table 4, and RB1388, data not shown) produced little, or no, alkaline phosphatase. All the presumptive pho deletion mutants tested produced the enzyme constitutively. The differential plot of enzyme activity versus dry weight gave a linear relationship during exponential growth. The enzyme specific activity was very similar for the series of strains derived from RB1180 (RB1190 is shown) and also strain SL1053, a spollA69 derivative of $\mathrm{RB} 1084$; this is consistent with the same gene being deleted in all strains.

Two alleles, phoS5 and phoS8, were originally described for the phoS locus. phoS5 gave a higher specific activity of alkaline phosphatase than phoS8 (Piggot \& Taylor, 1977). The 
specific activity in strain SL340 (spoIIA69 rif-2 phoS5) was very similar to that in the deletion strains derived from RB1180 (e.g. RB1190); this is consistent with phoS being deleted in the latter.

All the above strains carried the mutations spoIIA69 rif-2. The spoIIA69 mutation did not affect the constitutive level of alkaline phosphatase formation, as a ${ } p^{+}$transformant of RB1190, strain SL1059, had a very similar amount of enzyme to RB1190 (data not shown). However, the rif-2 mutation (or an otherwise cryptic mutation closely linked to rif) did affect the constitutive rate, as two $\mathrm{Spo}^{+} \mathrm{Rif}^{\mathrm{s}}$ strains produced about half the amount of enzyme as strains differing only in the spo and rif loci (compare RB1084 with SL1053, and SL344 with SL340).

\section{DISCUSSION}

A series of heat-resistant, phosphatase-constitutive mutants have been derived from strain RB1180. These mutants are considered to be deletion mutants since the method used in their isolation is known to generate deletions (Buxton, 1980). Moreover, although selection was made only for heat-resistance, the mutants have, in some cases, also become auxotrophic for proline and methionine besides having lost the repression of phosphatase synthesis by inorganic phosphate. Indeed, constitutivity for phosphatase provides a rapid screening method for deletions generated from $\mathrm{Xhi}^{-}$strains heat-inducible for PBSX.

The genes deleted almost certainly include $p h o S$ and sapA. The phosphatase phenotypes of all the deletions examined were the same as those of strains with the phoS5 mutation but otherwise isogenic (Table 4). Thus, phoS is epistatic to sapA (if indeed sapA is a separate gene) with respect to formation of vegetative alkaline phosphatase in the presence of inorganic phosphate. The deletions provide no evidence for any other phosphatase gene in the region. As the deletions remove the $p h o S$ gene and lead to the same constitutive enzyme activity as a point mutation in phoS, it seems reasonable to conclude that the phoS gene product exerts negative control on alkaline phosphatase synthesis in the presence of inorganic phosphate. The constitutive level of synthesis was affected by mutation to rifampinresistance, thus adding to the list of effects that such mutations can have (see Piggot et al., 1981).

Strain RB1037 and its derivatives sporulated poorly, and, in any case, the constitutive vegetative production of alkaline phosphatase masks any effects during sporulation (Piggot \& Taylor, 1977). Consequently, it was not possible to determine how the deletions affected the sporulation-associated production of alkaline phosphatase. There was, however, no obligatory requirement for any of the deleted region in forming a spore.

The method of deletion formation, involving the xhi mutation of PBSX, is of course only applicable to genes close to the PBSX prophage. A more generally applicable method of deletion formation is probably that involving the integration of a heat-inducible mutant of phage $\operatorname{SP} \beta(\operatorname{SP} \beta c 2)$ at secondary attachment sites and the subsequent isolation of heatresistant derivatives (Rosenthal et al., 1979; Zahler \& Korman, 1981).

The excellent technical assistance of Miss L. S. Drury in the present work, and of Mr P. N. Sockett who isolated the original deletion mutants, is gratefully acknowledged.

\section{REFERENCES}

Anagnostopoulos, C. (1960). Alkaline phosphatase formation in Bacillus subtilis. Federation Proceedings 19,48 .

Beckwith, J. \& Rossow, P. (1974). Analysis of genetic regulatory mechanisms. Annual Review of Genetics 8, 1-13.
BotT, K. F. \& Wilson, G. A. (1968). Metabolic and nutritional factors influencing the development of competence for transfection of Bacillus subtilis. Bacteriological Reviews 32, 370-378.

Brickman, E. \& Beckwith, J. (1975). Analysis of the regulation of Escherichia coli alkaline phosphatase 
synthesis using deletions and $\phi 80$ transducing phages. Journal of Molecular Biology 96, 307-316.

BuXToN, R. S. (1976). Prophage mutation causing heat inducibility of defective Bacillus subtilis bacteriophage PBSX. Journal of Virology 20, 22-28.

BuXTON, R. S. (1980). Selection of Bacillus subtilis 168 mutants with deletions of the PBSX prophage. Journal of General Virology 46, 427-437.

GARro, A. J., Leffert, H. \& MARMUR, J. (1970). Genetic mapping of a defective bacteriophage on the chromosome of Bacillus subtilis 168. Journal of Virology 6, 340-343.

GlenN, A. R. \& Mandelstam, J. (1971). Sporulation in Bacillus subtilis 168. Comparison of alkaline phosphatase from sporulating and vegetative cells. Biochemical Journal 123, 129-138.

Le HÉgarat, J.-C. \& ANAGNostopoulos, C. (1969) Localisation chromosomique d'un gène governant la synthèse d'une phosphatase alcaline chez Bacillus subtilis. Comptes rendus hebdomadaires des séances de l'Académie des sciences 269, 2048-2050.

Leighton, T. J. \& Dol, R. H. (1971). The stability of messenger ribonucleic acid during sporulation in Bacillus subtilis. Journal of Biological Chemistry 246, 3189-3195.

MARMUR, J. (1961). A procedure for the isolation of deoxyribonucleic acid from micro-organisms. Journal of Molecular Biology 3, 208-218.

Mikı, T., Minima, Z. \& IkedA, Y. (1965). The genetics of alkaline phosphatase formation in Bacillus subtilis. Genetics 52, 1093-1100.
Nukushina, J.-I. \& IKEDA, Y. (1969). Genetic analysis of the developmental processes during germination and outgrowth of Bacillus subtilis spores with temperature-sensitive mutants. Genetics 63, 63-74.

PIgGot, P. J. \& Coote, J. G. (1976). Genetic aspects of bacterial endospore formation. Bacteriological Reviews 40, 908-962.

Piggot, P. J. \& TAYLOR, S. Y. (1977). New types of mutation affecting formation of alkaline phosphatase by Bacillus subtilis in sporulation conditions. Journal of General Microbiology 102, 69-80.

Piggot, P. J., MoIR, A. \& Sмith, D. A. (1981). Advances in the genetics of Bacillus subtilis differentiation. In Sporulation and Germination, $\mathrm{pp}$. 29-39. Edited by H. Levinson, A. L. Sonenshein \& D. Tipper. Washington, D.C.: American Society for Microbiology.

Potvin, B. W., Kelleher, R. J. \& Gooder, H. (1975). Pyrimidine biosynthetic pathway of Bacillus subtilis. Journal of Bacteriology 123, 604-615.

Rosenthal, R., TOYe, P. A., Korman, R. Z. \& ZAHLER, S. A. (1979). The prophage of SP $\beta \mathrm{c} 2 \mathrm{dc} 2 \mathrm{dcitK}_{\mathrm{I}}$, a defective specialized transducing phage of Bacillus subtilis. Genetics 92, 721-739.

ZAHLER, S. A. \& Korman, R. Z. (1981). Specialised transduction with Bacillus subtilis phage $\mathrm{SP} \beta$. In Sporulation and Germination, pp. 101-103. Edited by H. Levinson, A. L. Sonenshein \& D. Tipper. Washington, D.C.: American Society for Microbiology. 